\title{
Expressão imunohistoquímica de P53 e Ki-67 na carcinogênese esofágica induzida pela dietilnitrosamina: modelo experimental
}

\author{
Immunohistochemical expression of P53 and Ki-67 in diethylnitrosamine- \\ induced carcinomas esophageal: experimental model
}

\author{
Miguel Angelo Martins de Castro Junior' TCBC-RS ; Cleber Dario Pinto Kruel, TCBC-RS²; Luise Meurer³; \\ Angela Potter de Castro ${ }^{4}$
}

\section{R E S U M O}

\begin{abstract}
Objetivo: Avaliar a expressão imunohistoquímica de p53 e ki-67 na carcinogênese esofágica induzida quimicamente através do uso de dietilnitrosamina, em um grupo de 100 camundongos fêmeas. Métodos: O estudo experimental foi realizado com quatro grupos de animais, onde os grupos I e II foram considerados controles, sendo diferenciados por gavagem esofágica, uma vez semana, com água fria (temperatura ambiente) ou quente $\left(60^{\circ}-70^{\circ} \mathrm{C}\right)$. E os grupos III e IV foram considerados estudos, os quais receberam dietilnitrosamina por três dias consecutivos semanalmente, também sendo diferenciados por gavagem, uma vez por semana, com água fria ou quente. $\mathrm{O}$ estudo apresentou datas progressivas de sacrifícios com coleta de peças esofágicas, que iniciava aos 30 dias de experimento e terminava aos 150 dias. Demonstrou-se que não houve diferença na incidência tumoral quando foi acrescida a variável temperatura da água; provavelmente devido ao episódio único semanal que era adicionado ao animal em experimentação. Resultados: A análise imunohistoquímica do p53 não evidenciou diferença estatística durante a evolução da carcinogênese até 150 dias, porém quando analisado a relação com alterações patológicas demonstra-se que apresenta significância em relação à patologia baixo grau de displasia, alto grau e carcinoma. Conclusão: A análise imunohistoquímica do ki-67 demonstrou diferença estatística durante a evolução da carcinogênese a partir do dia 120 de experimento e quando analisada a relação com alterações patológicas demonstrou-se que apresenta significância também em relação à lesão intraepitelial de alto grau e carcinoma.
\end{abstract}

Descritores: Marcadores tumorais biológicos. Esôfago. Dietilnitrosamina. Carcinoma de células escamosas. Transcrição genética.

\section{INTRODUÇÃO}

C arcinoma epidermóide e adenocarcinoma, são responsáveis por $95 \%$ dos tumores esofágicos primários ${ }^{1}$. 0 carcinoma epidermóide do esôfago é neoplasia com alta taxa de mortalidade e distribuição geográfica peculiar. A etiologia dele está comprovadamente ligada ao uso do tabaco e do álcool, em áreas não endêmicas. Outros fatores etiológicos têm sido implicados e estudados: chás em temperaturas elevadas, ervas com carcinógenos e principalmente compostos $\mathrm{N}$-nitrosos ${ }^{1-3}$.

P53, um dos gens responsáveis pelo ciclo cellular, tem papel fundamental nas neoplasias humanas. Principal regulador negativo do ciclo celular, estando envolvido na divisão, diferenciação celular e apoptose. Com o dano a algum segmento de DNA, há aumento dos níveis de proteína codificada por este gene, o que causa parada deste ciclo e permite que o DNA seja reparado, ou que seja programada a apoptose ${ }^{4}$. A inativação da proteína p53 por mutação, perda, seqüestração ou ligação a outras proteínas como proteínas virais, pode levar ao aumento da proli- feração, à instabilidade genômica e à perda de importantes mecanismos de controle do ciclo celular ${ }^{5}$.

O Ki-67 é um antígeno nuclear associado com a proliferação celular, encontrado em todo o ciclo celular (fases G1, S, G2, M) e ausente em G0. Através da análise imunohistoquímica, tem-se buscado correlacionar sua expressão com o comportamento tumoral. O uso do Ki-67 está restrito ao tecido à fresco, pois o epítopo não sobrevive à fixação histológica de rotina em formaldeído. MIB1 é um verdadeiro anti-Ki-67 equivalente, que pode ser empregado em tecidos fixados em f0ormalina e em tecidos rotineiramente processados com recuperação antigênica através de microondas. Uma das técnicas imunohistoquímicas na avaliação da proliferação celular é a detecção do Ki-676,7.

Dietilnitrosamina (DEN) é um carcinógeno químico que induz tumores em muitas espécimes animais, particularmente no sistema respiratório, digestivo alto, fígado e rins 8 .

Este trabalho investigou a evolução de carcinomas epidermóides de esôfago induzidos por dietilnitrosamina

\footnotetext{
Trabalho realizado na Unidade de Experimentação Animal, Centro de Pesquisa do Hospital de Clínicas de Porto Alegre, RS- BR.

+ Dissertação de Mestrado como requisito à obtenção do Grau de Mestre. Programa de Pós-Graduação: Ciências em Gastroenterologia, UFRGS - BR.

1. Professor de Cirurgia da Universidade Federal do Rio Grande - FURG - BR; 2. Professor de Cirurgia, Universidade Federal do Rio Grande do Sul - UFRGS - BR; 3. Patologista do Departamento de Patologia do HCPA; 4. Doutora pela UNIFESP.
} 
em camundongos, durante um período de 150 dias. A avaliação patológica foi complementada com analise imunohistoquímica do P53 e Ki-67.

\section{MÉTODOS}

Este trabalho foi submetido à análise da Comissão Científica e da Comissão de Pesquisa e Ética em Saúde, que é reconhecida pela Comissão Nacional de Ética em Pesquisa (CONEP)/MS, como o Comitê de Ética em Pesquisa do Hospital de Clínicas de Porto Alegre e pelo Oftice For Human Research Protections (OHRP)/USDHHS, como o Institucional Review Board (IRBO000921), sendo aprovado na data de 13 de outubro de 2003, recebendo o número de protocolo: 03345.

Nesse trabalho foram utilizados camundongos (Mus musculus, cepa CF1), num total de 100 fêmeas, com 60 dias de vida e peso médio inicial de 30 gramas, provenientes do biotério da Fundação Estadual de Produção e Pesquisa em Saúde. Os animais foram mantidos na Unidade de Experimentação Animal, do Centro de Pesquisa do Hospital de Clínicas de Porto Alegre, em condições estáveis de umidade, temperatura $\left(19^{\circ}-21^{\circ} \mathrm{C}\right)$, fluxo contínuo de ar e ciclo de 12 horas de claro e escuro (luz 9:00h - 21:00h). Todos os animais foram adaptados a estas condições, sete dias antes de entrarem em experimento nesta mesma unidade. Mantidos em gaiolas plásticas, dez por recipiente, com grade metálica servindo de tampa, e fundo forrado com serragem. Estas eram higienizadas conforme rotina da Unidade de Experimentação Animal.

\section{Tratamento}

A partir do primeiro dia de experimento, foi acrescido o carcinógeno DEN (diethylnitrosamine), na concentração 0,04mg/1000ml, na água dos animais do Grupo Estudo, e oferecida semanalmente, por três dias consecutivos (terças, quartas e quintas-feiras), para indução de tumores, conforme modelo9,10, mantendo-se alimentação padrão.

\section{Desenho do Experimento}

Os animais foram distribuídos em quatro grupos: -Grupo I e II (10 animais/grupo) receberam água ad libitum, como única fonte hídrica, durante todo o experimento, renovada às segundas, quartas e sextas-feiras; e gavagem esofágica, uma vez por semana, com água fria (temperatura ambiente) ou quente $\left(60-70^{\circ} \mathrm{C}\right)$, respectivamente.

-Grupo III e IV (40 animais/grupo) receberam água ad libitum, como fonte hídrica, de sextas a terças-feiras; nas terças-feiras, a água era substituída por uma solução de DEN, que permanecia por 72 horas (terças, quartas e quintas-feiras); e gavagem, uma vez por semana, com água fria (temperatura ambiente) ou quente $\left(60-70^{\circ} \mathrm{C}\right)$, respectivamente.
Os animais foram sacrificados em diferentes períodos. No grupo controle (I e II), sacrifício de metade da amostra no dia 30 de experimento, e restantes da amostra, no dia 150. No grupo experimento (III e IV), sacrifício de cinco animais de cada amostra no dia 30,60, 90,120 de experimento, e os 20 animais restantes dos grupos, no dia 150.

\section{Preparação das Amostras}

Cada animal do grupo foi sacrificado em câmara de $\mathrm{CO}_{2}$. O esôfago foi dissecado através de incisão mediana xifopúbica toracoabdominal, e o lúmen aberto longitudinalmente expondo a mucosa. O material destinado à patologia era mantido estendido sobre a cortiça e acondicionado em potes plásticos, devidamente identificados pelo grupo, com formol a $10 \%$. As peças esofágicas dos 20 animais do grupo estudo (Grupo III e IV), sacrificados aos 150 dias de experimento, foram submetidos ao exame de contagem tumoral (lesões maiores ou iguais a 1 $\mathrm{mm}$ ) e, depois, sorteadas cinco das peças esofágicas destes animais, as quais foram enviadas para estudo histopatológico.

\section{Análise Histopatológica}

Os espécimes esofágicos foram enrolados sobre si mesmos, processados e embebidos em parafina. Lâminas foram preparadas e coradas com hematoxilina e eosina. Segmentos histológicos foram analizados por microscopia ótica para identificacão de aterações anatomopatológicas, classificadas conforme estudos pré$\operatorname{vios}^{9,10}$.

\section{Avaliação Imunohistoquimica}

As amostras com cortes com espessura de $5 \mu$ foram submetidos à rotina de imunohistoquímica. Utilizado anticorpo primário monoclonal de camundongo da marca DAKO Corporation antiproteína p53 (Clone Pab240) e um anticorpo monoclonal primário de camundongo antiproteína ki-67 (Clone MIB-5). Os anticorpos primários foram incubados por 12 horas, a $4^{\circ} \mathrm{C}$, nas diluições de 1:50 para Ki-67 e 1:50 para p53, seguidos da aplicação do complexo estreptavidina-biotina-peroxidase (LSAB, Dako) e revelação com diaminobenzidina tetraidroclorido (Kit DAB, Dako). As reações tiveram como controles positivos, carcinoma de cólon para p53 e linfonodo para Ki-67, sendo o controle negativo realizado sem a utilização do anticorpo primário. Para p53 e ki67 foram considerados como positivos, na análise imunohistoquímica (Figura 1), as lâminas que apresentaram mais de $10 \%$ de núcleos celulares intensamente corados, por campo microscópico de 400 aumentos. As lâminas foram examinadas por dois patologistas do Serviço do Hopsital de Clínicas de Porto Alegre, com experiência na análise de amostras animal.

\section{Análise Estatística}

Os dados coletados foram processados e analisados com o auxílio dos programas Epi Info V6.04 e Statistica. Os grupos foram comparados pelo uso do teste ANOVA, 

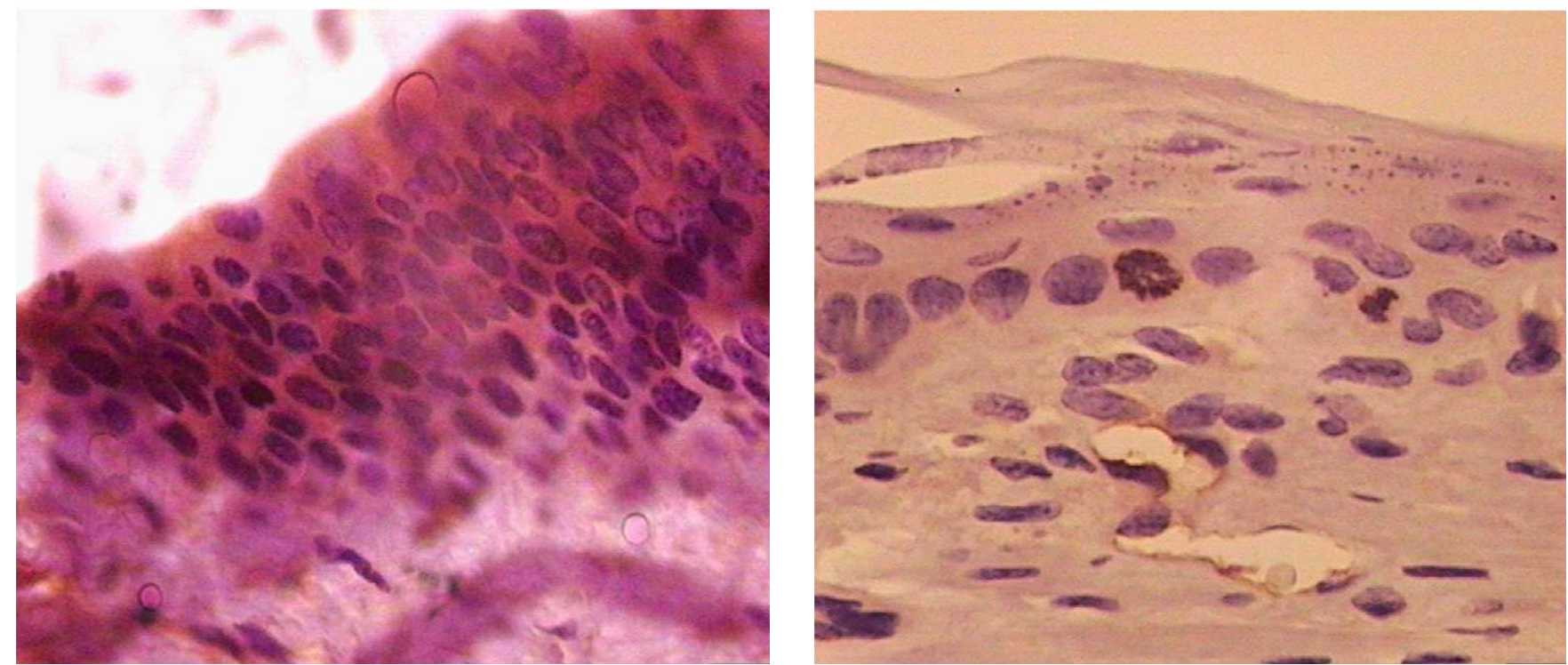

Figura 1 - Expressão imunohistoquímica de P53(a) e Ki-67(b) positivas (200x).

com localização de diferenças significativas pelo teste de TUKEY, Teste $t$ para diferença entre proporções e teste quiquadrado de PEARSON. O nível de significância dos testes foi estabelecido para um valor $p<0,05$.

\section{RESULTADOS}

Foram registrados três óbitos, sendo todos do Grupo IV, dois óbitos com 45 dias de experimento, provavelmente relacionados com aspiração pulmonar e um óbito ao final do experimento por debilidade física.

Não foi evidenciado, presença à necropsia, de tumorações em outras localizações de fácil identificação macroscópica.

Não foram detectadas alterações patológicas nos Grupos I e II, cujos esôfagos serviram de padrão de normalidade.

Não houve diferença relevante nas características macroscópica dos tumores nos grupos estudo e, embora não tenham sido objeto especial de atenção, variações na forma e dimensões dos tumores foram comuns aos Grupos III e IV, assim como multiplicidade. O número de tumores, no dia 150, foi maior no Grupo IV, com 13 tumores em 17 peças esofágicas; seguido do Grupo III, com 14 tumores em 20 peças esofágicas. Estes achados não alcançaram diferença estatística $(p=0,6854)$. Não havendo, por este resultado diferença entre os grupos que receberam $D E N$ com variação entre gavagem água quente ou fria. Similarmente, não houve diferença relacionada a precocidade de aparecimento ou gravidade das lesões observadas nos grupos III e IV. As alterações observadas nas amostras experimentais, são apresentadas na Figura 2.

A figura 3 demonstra, respectivamente, os resultados da análise imunohistoquímica do p53, considerado positivo e aumentando com o tempo (90,120 and 150 dias), e do Ki-67, também positivo e tempo-dependente.
Achados Anatomopatológicos - DEN Geral

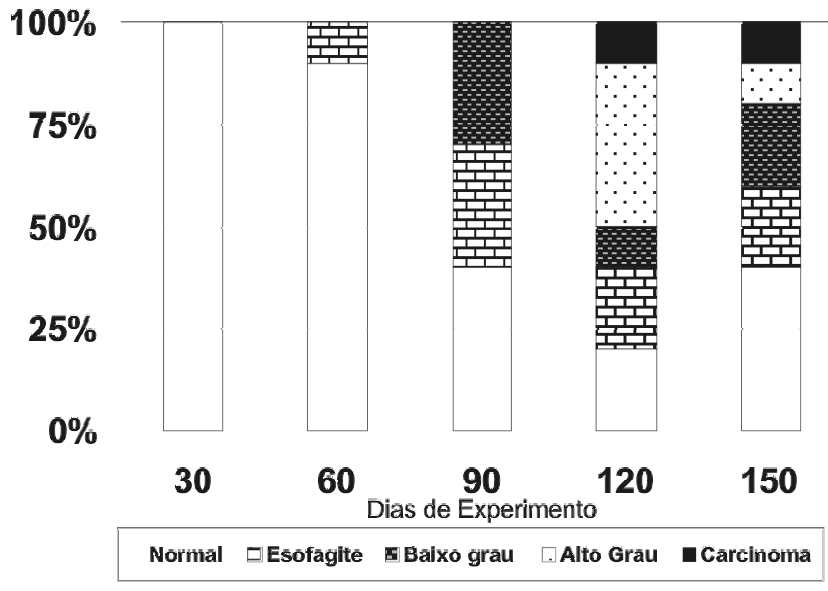

Figura 2 - $\quad$ Achados histológicos durante o experimento nos animais que receberam DEN independente do tipo de gavagem.

A evolução da expressão imunohistoquímica de p53 e ki-67(Figuras 4 e 5), em percentagem, durante a carcinogênese, sendo utilizado o teste de análise de variância post-hoc (Teste Tukey). Ficou demonstrada diferença estatística somente para a expressão imunohistoquímica de Ki-67, quando analisado o grupo estudo como uma amostra única ( $p=0,01880)$, a partir do dia 120 de experimento.

Os achados de expressão imunohistoquímica de p53 e Ki-67 foram comparados (Teste quiquadrado de Pearson) com a variabilidade de achados patológicos de toda a amostra (Tabela 1), havendo significância quanto à expressão negativa em relação aos achados de epitélio normal e expressão positiva para lesão intraepitelial de alto grau e carcinoma.

Quando comparado o achado ao epitélio normal apenas, e não toda a amostra, alcançou significância além das anteriores descritas, a lesão epitelial de baixo grau. 
Achados p53 - Grupo Estudo (III e IV)

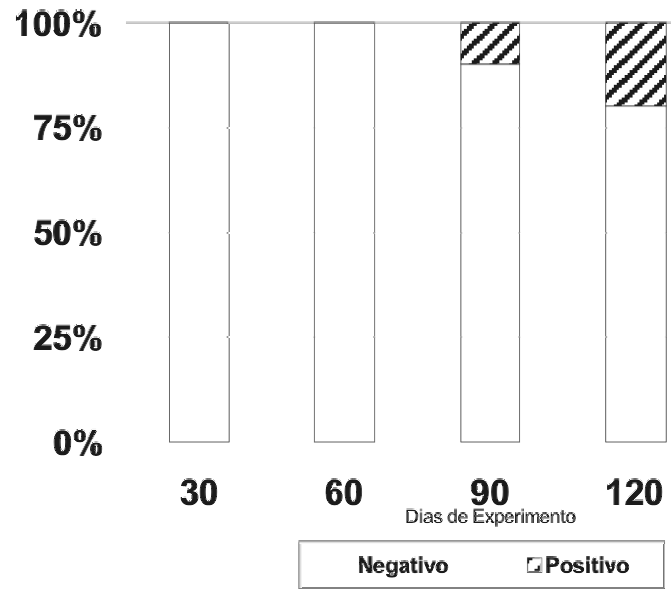

Achados Ki-67 - Grupo Estudo (III e IV)

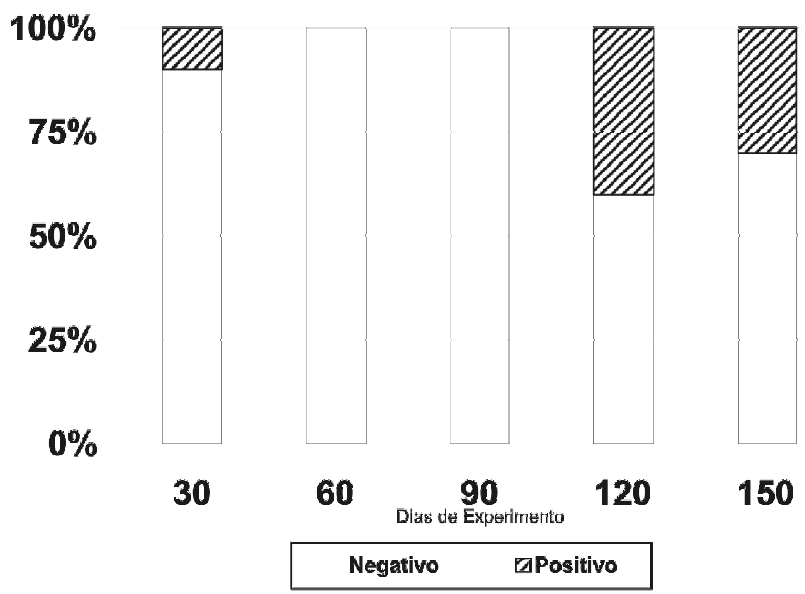

Figura 3 - Expressão imunohistoquímica do P53(a) e Ki-67(b) durante o experimento, em animais tratados com DEN e gavagem com água quente ou fria (groups III and IV).

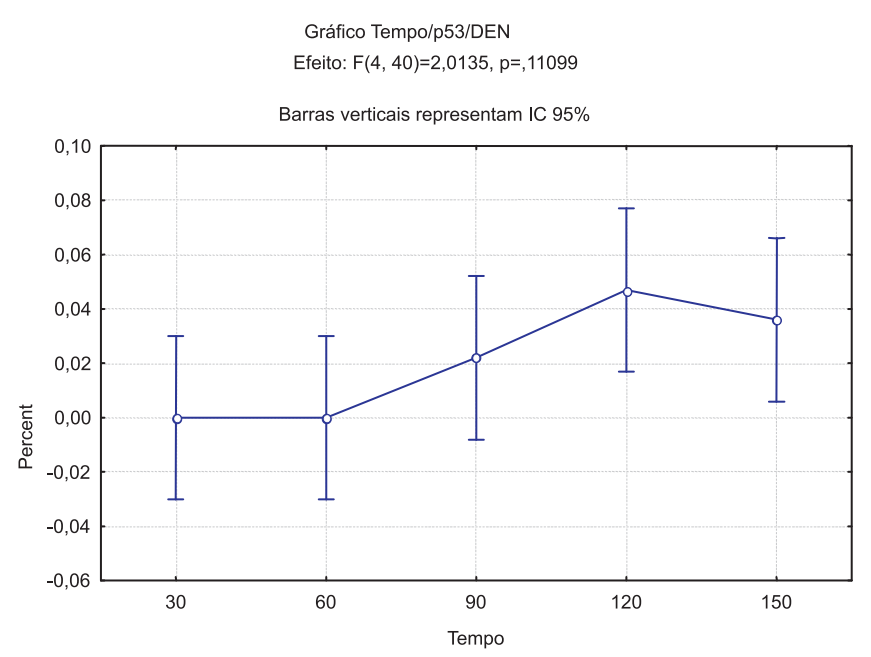

Figura 4 - $\quad$ Aparecimento da expressão imunohistoquímica de p53 na carcinogênese nos grupos que receberam DEN (independente da gavagem).

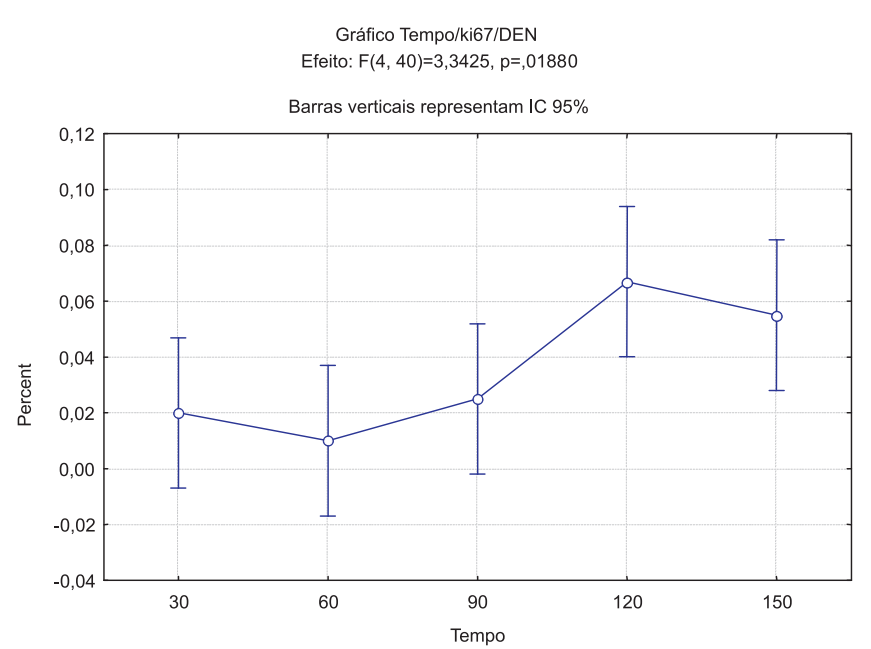

Figura 5 - $\quad$ Aparecimento da expressão imunohistoquímica de Ki67 na carcinogênese nos grupos que receberam DEN (independente da gavagem).

\section{DISCUSSÃO}

Optou-se pelo emprego de fêmeas, neste trabaIho, por ser conhecida a questão da morte de animais envolvidos em conflitos para estabelecimento territorial, atitude quase exclusiva dos machos ${ }^{9}$.

A concentração de DEN foi a preconizada em outros modelos experimentais, tendo em vista diminuir a hepatotoxicidade ${ }^{8,9,11}$. A administração na água de beber tem dupla vantagem: da eficiência e da mínima necessidade de manipulação dos animais, embora permita variações de consumo. A alimentação empregada foi semelhante àquela usada em diversos experimentos e não deve ter influído no processo de carcinogênese.

O período para análise dos resultados foram determinados em concordância com estudos prévios de carcinogênese esofágica induzidos por dietilnitrosamina ${ }^{9,11}$. Desta forma, o experimento acompanhou a cronologia da histogênese do carcinoma escamoso esofágico e propiciou acompanhar as expressões imunohistoquímicas do p53 e Ki-67. Kruel ${ }^{9}$ demonstrou, em seu experimento, o primeiro carcinoma invasor no tempo 120, dois outros no tempo 150 e outros 26 no tempo 180, evidenciando uma clara eclosão de tumores invasores a partir do tempo 150.

Nossos resultados somam-se aos estudos experimentais desta linha de pesquisa de carcinogênese esofágica. O processo carcinogênico foi caracterizado com a evolução das lesões, culminando com aparecimento de carcinomas no tempo 120 e 150, com gavagem de água quente. Não sendo objeto principal desta dissertação o número de tumores, justificando o número pequeno de animais por sacrifício, pois a metodologia já está difundida na literatura médica, o modelo experimental torna-se útil para, agora sim, o estudo da carcinogêse..

Wang ${ }^{12,13}$ demonstrou, que existe acúmulo da proteína p53 com o aumento das freqüências da proliferação 
Tabela 1 - Alterações microscópicas e expressão imunohistoquímica do P53 e Ki-67. (L.I., lesão intraepithelial).

\begin{tabular}{llcccc}
\hline Marcador & \multicolumn{5}{c}{$\%$ (positivo/número total de espécimes) } \\
\cline { 2 - 6 } & Normal & Esofagite & L.I. Baixo Grau & L.I.Alto Grau & Carcinoma \\
\hline p53 & $0 \%(0 / 29)$ & $0 \%(0 / 8)$ & $33 \%(2 / 6)^{\mathrm{a}}$ & $40 \%(2 / 5)^{\mathrm{b}}$ & $100 \%(2 / 2)^{\mathrm{c}}$ \\
Ki-67 & $3 \%(1 / 29)$ & $0 \%(0 / 8)$ & $33 \%(2 / 6)$ & $60 \%(3 / 5)^{\mathrm{d}}$ & $100 \%(2 / 2)^{\mathrm{e}}$ \\
\hline
\end{tabular}

${ }^{a}$ Teste Quiquadrado de Pearson, $p=0.025$ entre epitélio normal e L. I. de baixo grau

'Teste Quiquadrado de Pearson, $p=0.017$ entre epitélio normal e L I de alto grau

'Teste Quiquadrado de Pearson, $p=0.002$ entre epitélio normal e carcinoma

${ }^{d}$ Teste Quiquadrado de Pearson, $p=0.05$ entre epitélio normal e L. I. de alto grau

'Teste Quiquadrado de Pearson, $p=0,006$ entre epitélio normal e carcinoma

celular em hiperplasia, displasia, carcinoma in situ e carcinoma escamocelular. Estudou espécimes de ressecção esofágica, realizando biópsias de $1 \mathrm{~cm}^{2}$ na zona tumoral, na mucosa da margem da lesão na extremidade distal da peça cirúrgica ${ }^{12}$. Realizou estudo imunohistoquímico das lesões em relação ao p53. Demonstrou prevalência de 0\% em epitélio normal, 78\% de p53 positivo para hiperplasia, 92\% para displasia e entre $80-82 \%$ para o carcinoma in situ e invasor epidermóide.

Embora o gene p53 esteja freqüentemente mutado em muitos tipos de câncer, o momento (tempo) da ocorrência desta mutação durante progressão para o câncer é extremamente variável de um tumor para outro. É demonstrado no câncer colo-retal que mutações no p53 ocorreram na transição entre adenoma tardio e carcinoma in situ, logo em fases tardias da carcinogênese. Similares achados são descritos para câncer de próstata e mama. Em contraste, mutações no p53 precocemente são detectadas em outros vários tumores ${ }^{14,15}$, como câncer de pulmão, de pele não melanoma e esofágicos ${ }^{16,17}$. Nestes, são frequentemente detectadas em lesões hiperplásicas e displásicas, bem como em aparente tecido normal ao redor do tumor $^{18}$.

Não foi evidenciado, durante a avaliação do material da dissertação, imunoexpressão em áreas que não eram de interesse e muito menos nos casos de epitélio normal, quando avaliava-se o marcador p53, contrariando, parcialmente, os resultados de Oliver. Porém, o aparecimento precoce, estatisticamente significativo, da detecção da proteína já em lesões intraepiteilais de baixo grau, realçam a sua importância precoce na carcinogênese.

A imunohistoquímica não define a existência de mutações genéticas, mas existem dados que sugerem a relação entre o prolongamento da estabilidade da proteína p53 e, conseqüentemente, a sua expressão imunohistoquímica, com mutações ocorrendo no epitélio esofágico, principalmente as mutações do tipo missense ${ }^{19,20}$.

É possível que o acúmulo da proteína p53 em células tumorais possa, em alguns casos, indicar a existência de um defeito regulatório na seqüência codificadora protéica do gene, ao invés de uma mutação. Diversos investigadores observaram discrepâncias entre a expressão da proteína p53 e a presença de mutações e, além, pode ocorrer a mutação no gene p53, sem aumento na expressão da proteína ${ }^{21,22}$

Foi demonstrado que a porcentagem de células positivas à imunohistoquímica para Ki-67, nos casos de carcinoma epidermóide de esôfago, correlacionou-se com o grau de diferenciação encontrada á histologia ${ }^{23}$ e este achado correlacionou-se com a presença de metástases à distância e sobrevida. Estes achados podem ser transponíveis ao p53.

Diferente de estudos prévios 24,25 , a administração de água quente (temperatura entre $60-70^{\circ} \mathrm{C}$ ), tanto nos animais do grupo controle (II), como, principalmente, nos animais no grupo estudo (IV), não apresentou variação estatística aos resultados de seus grupos pares (Grupo I e III, respectivamente). Estes achados contrariam os achados, nesses trabalhos, como em outros: que a ação térmica promoveria o aparecimento precoce e comportamento mais agressivo das lesões expansivas neoplásicas esofágicas. Talvez este achado possa ser justificado pelo " $n$ " de cada amostra ser pequeno, proporcionalmente à divisão entre os grupos, ou ainda pela administração única apenas semanal, trazendo pouco efeito térmico esofágico. Do mesmo modo, o composto nitroso utilizado foi diferente ao que foi disponibilizado aos animais nesta dissertação.

Os achados de expressão imunohistoquímica, durante a carcinogênese sob efeito de dietilnitrosamina, revelam a progressão de resultados de captação de proteína p53 e marcado aumento da proliferação celular, traduzido pelo aumento do Ki-67. Apenas o Ki-67 apresentou poder para demonstrar, a partir do dia 150 de experimento, elevação significativa, sugerindo que, entre os dias 120 e 150, houve o descontrole do ciclo celular, reproduzindo grande atividade celular, podendo-se sugerir o início mutagênico do processo.

Os achados dos marcadores de Ki-67 e p53 vão ao encontro aos de Pêra ${ }^{26}$. É demonstrado aparecimento de Ki-67, desde o início do processo e sendo negativo para p53. Com a evolução do processo, concomitante ao aparecimento das primeiras displasias, o p53 torna-se positivo e o Ki-67 aumenta sobremaneira a sua imunoexpressão, chegando aos casos de carcinoma, onde ambos são freqüentemente positivos. As expressões imunohistoquímicas, com relação aos achados patológicos, 
demonstram que ambos os marcadores apresentam variabilidade precoce em relação a estes. Foi evidenciado, já nas lesões intraepiteliais, positividade clínica das peças cirúrgicas. Conclue-se que a análise imunohistoquímica do P53 e Ki-67 apresentou relação com o aparecimento das lesões patológicas e tendência de aumento em relação a variável tempo.

Não houve diferença no efeito da temperatura da água para gavagem em relação ao número de tumores em 150 dias de experimento.

\section{A B S T R A C T}

Objective: To evaluate the expression of P53 and Ki-67 during esophageal diethylnitrosamine (DEN)-induced carcinogenesis in 100 mice by immunohistochemistry. Methods: The animals were assigned to 4 groups, receiving water and food ad libitum. Control groups I and II received weekly esophageal gavage with cold (room temperature) or hot $\left(60-70^{\circ} \mathrm{C}\right)$ water, respectively. Experimental groups III and IV were treated with DEN for 3 consecutive days during the week, and one weekly gavage as above. The mice were sacrificed in different periods from day 30 to day 150 after the beginning of the experiment, for collection of esophageal samples which were then submitted to microscopic and immunohistochemical analyses. The temperature of the water administered by gavage was not related to the frequency of esophageal tumors. Results:The expression of Ki-67 was significantly higher in high-grade intraepithelial lesion (I.L.), and the expression of P53 was also higher in low-grade I.L. Conclusion:The results emphasize the direct relationship of the carcinogenic process with early cell alterations detected by immunohistochemistry.

Key words: Tumor markers, biological. Esophagus. Diethylnitrosamine. Carcinoma, squamous cell. Transcription, genetic.

\section{REFERENCIAS}

1. Souza RF. Molecular and biologic basis of upper gastrointestinal malignancy-esophageal carcinoma. Surg Oncol Clin N Am. 2002;11(2):257-72

2. Barrett JH, Parslow RC, McKinney PA, Law GR, Forman D. Nitrate in drinking water and the incidence of gastric, esophageal, and brain cancer in Yorkshire, England. Cancer Causes Control. 1998;9(2):153-9.

3. Barros SGS, Ghisolfi ES, Luz LP, Barlem GG, Vidal RM, Wolff FH, et al. Mate (chimarrão) é consumido em alta temperatura por população sob risco para o carcinoma epidermóide de esôfago. Arq Gastroenterol. 2000;37(1):25-30.

4. Lane DP. Cancer. p53, guardian of the genome. Nature. 1992;358(6381):15-6.

5. Klumb CE, Cavalcanti Júnior GB. Avaliação dos métodos de detecção das alterações do gene e proteína P53 nas neoplasias linfóides. Rev Bras Hematol Hemoter. 2002;24(2):111-25.

6. Xu M, Jin YL, Fu J, Huang H, Chen SZ, Qu Pet al. The abnormal expression of retinoic acid receptor-beta, p 53 and Ki67 protein in normal, premalignant and malignant esophageal tissues. World J Gastroenterol. 2002;8(2):200-2.

7. Muskhelishvili L, Latendresse JR, Kodell RL, Henderson EB. Evaluation of cell proliferation in rat tissues with BrdU, PCNA, Ki-67(MIB-5) immunohistochemistry and in situ hybridization for histone mRNA. J Histochem Cytochem. 2003;51(12):1681-8.

8. Rubio CA, Liu FS, Chejfec G, Sveander M. The induction of esophageal tumors in mice: dose and time dependency. In Vivo. 1987;1(1):35-8.

9. Kruel CDP, Pan Chacon J. Classificação citopatológica das lesões precursoras do carcinoma escamoso do esôfago: modelo experimental em camundongos [dissertação]. São Paulo (SP): Escola Paulista de Medicina; 1992.

10. W.H.O. International histologic Classification of Tumors (1977) 18. Histological typing of gastric and oesophageal tumors. Geneva.

11. Velho AV, Kruel CDP. A influência do chá preto sobre a gênese tumoral esofágica induzida pela dietilnitrosamina: modelo experimental em camundongos [dissertação]. Porto Alegre (RS): Universidade Federal do Rio Grande do Sul; 1998.

12. Wang LD, Hong JY, Qiu SL, Gao H, Yang CS. Accumulation of p53 protein in human esophageal precancerous lesions: a possible early biomarker for carcinogenesis. Cancer Res. 1993;53(8): 1783-7.
13. Dong Wang L, Bin Yue W, Zhou Y, Wei Feng C, Liu B, Zhou Q et al. Endoscopic screening and determination of p53 and proliferating cell nuclear antigen in esophageal multistage carcinogenesis: a comparative study between high- and low-risk populations in Henan, northern China. Dis Esophagus. 2002;15(1):80-4.

14. Brennan JA, Boyle JO, Koch WM, Goodman SN, Hruban RH, Eby YJ et al. Association between cigarette smoking and mutation of the p53 gene in squamous-cell carcinoma of the head and neck. N Engl J Med. 1995; 332(11):712-7.

15. Yang CS, Wang ZY. Tea and cancer. J Natl Cancer Inst. 1993;85:1038-49

16. Gao H, Wang LD, Zhou Q, Hong JY, Huang TY, Yang CS. p53 tumor suppressor gene mutation in early esophageal precancerous lesions and carcinoma among high-risk populations in Henan, China. Cancer Res. 1994; 54(16):4342-6.

17. Hashimoto N, Tachibana M, Dhar DK, Yoshimura H, Nagasue N. Expression of p53 and RB proteins in squamous cell carcinoma of the esophagus: their relationship with clinicopathologic characteristics. Ann Surg Oncol. 1999; 6(5):489-94.

18. Olivier M, Hussain SP, Fromentel CC. TP53 mutation spectra and load: a tool for generating hypotheses on the etiology of cancer. In: Buffler P, Rice J, Baan R, Bird M, Boffetta P. Mechanisms of carcinogenesis: contributions of molecular epidemiology. IARC Scientific Publications; 2004.

19. Harris C, Hollstein M. Clinical implications of the P53 tumor suppressor gen. N Eng J Med. 1993;329(18):1318-26.

20. Wagata $T$, Shibagaki I, Imamura M, Shimada Y, Toguchida J, Yandell DW et al. Loss of 17p, mutation of the p53 gene, and overexpression of p53 protein in esophageal squamous cell carcinomas. Cancer Res. 1993;53(4):846-50.

21. Casson AG, Tammemagi M, Eskandarian S, Redston M, McLaughlin J, Ozcelik H. p53 alterations in oesophageal cancer: association with clinicopathological features, risk factors, and survival. Mol Pathol. 1998; 51(2):71-9.

22. Coggi G, Bosari S, Roncalli M, Graziani D, Bossi P, Viale G et al. p53 protein accumulation and p53 gene mutation in esophageal carcinoma. A molecular and immunohistochemical study with clinicopathologic correlations. Cancer. 1997:79(3):425-32.

23. Matsumoto M, Natsugoe S, Nakashima S, Shimada M, Nakano S, Kusano $C$ et al. Biological evaluation of undifferentiated carcinoma of the esophagus. Ann Surg Oncol. 2000;7(3):204-9.

24. Kruel CDP, Gurski R, Cavazzola LT. Hot-water effect in the esophageal carcinogenesis experimental model in mice [abstract]. 
Sixth World Congress of International Society for Diseases of the Esophagus, Milan, Italy. 1995. p.199.

25. Li ZG, Shimada Y, Sato F, Maeda M, Itami A, Kaganoi J et al. Promotion effects of hot water on N-nitrosomethylbenzylamineinduced esophageal tumorigenesis in F344 rats. Oncol Rep. 2003;10(2):421-6.

26. Pera M, Fernandez PL, Pera M, Palacín A, Cardesa A, Dasenbrock C, Tillman T, Mohr U. Expression of cyclin D1 and p53 and its correlation with proliferative activity in the spectrum of esophageal carcinomas induced after duodenal content reflux and 2,6dimethylnitrosomorpholine administration in rats. Carcinogenesis. 2001;22(2):271-7.
Recebido em 10/02/2009

Aceito para publicação em 31/03/2009

Conflito de interesse: nenhum

Fonte de financiamento: Nenhuma

\section{Como citar esse artigo:}

Castro Júnior MAM, Kruel CDP, Meurer L, Castro AP. Expressão imunohistoquímica de p53 e ki-67 na carcinogênese esofágica induzida pela dietilnitrosamina: modelo experimental. Rev Col Bras Cir. [periódico na Internet] 2010; 37(2). Disponível em URL: http://www.scielo.br/rcbc

\section{Endereço para correspondência:}

Miguel Angelo Martins de Castro Junior

E-mail: miguel_jr@me.com 